\title{
Deformación tibial en lactante
}

\author{
E. García Barrecheguren y J.L. Beguiristáin Gúrpide
}

Departamento de Cirugía Ortopédica y Traumatología. Clínica Universitaria de Navarra. Pamplona. España.

\section{Caso clínico}

Varón, lactante de 2 meses, nacido por parto eutócico con un peso de $3.500 \mathrm{~g}$ y $52,5 \mathrm{~cm}$ de longitud. Sin antecedentes mórbidos en el período neonatal. Sin antecedentes traumáticos.

\section{Exploración física}

Alteración de la morfología normal de la extremidad inferior izquierda con deformidad de la cara posterior de la pantorrilla a nivel del tercio mediodistal (fig. 1). Sin dolor a la palpación de la zona ni a la movilización de la extremidad (tobillo, rodilla y cadera). Sin presencia de
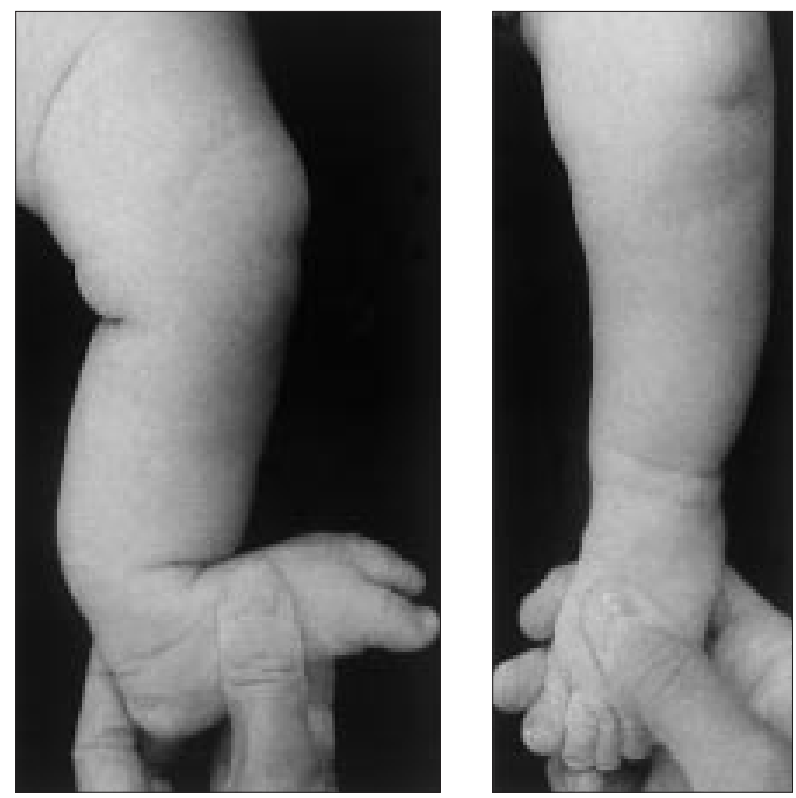

Figura 1. Deformidad de tercio distal de pantorrilla, incurvada hacia posterior, que se acentúa en talo (a los 2 meses). circulación colateral o cambios tróficos en la zona afectada. La deformidad es más manifiesta si se coloca el pie en talo (antiequino).

\section{Radiografía anteroposterior y lateral de pierna izquierda}

Deformidad de dirección posterior y medial de tibia y peroné con zona de esclerosis en el ápex de la curvatura (fig. 2).

\section{Pregunta}

1. ¿Cuál es su diagnóstico?
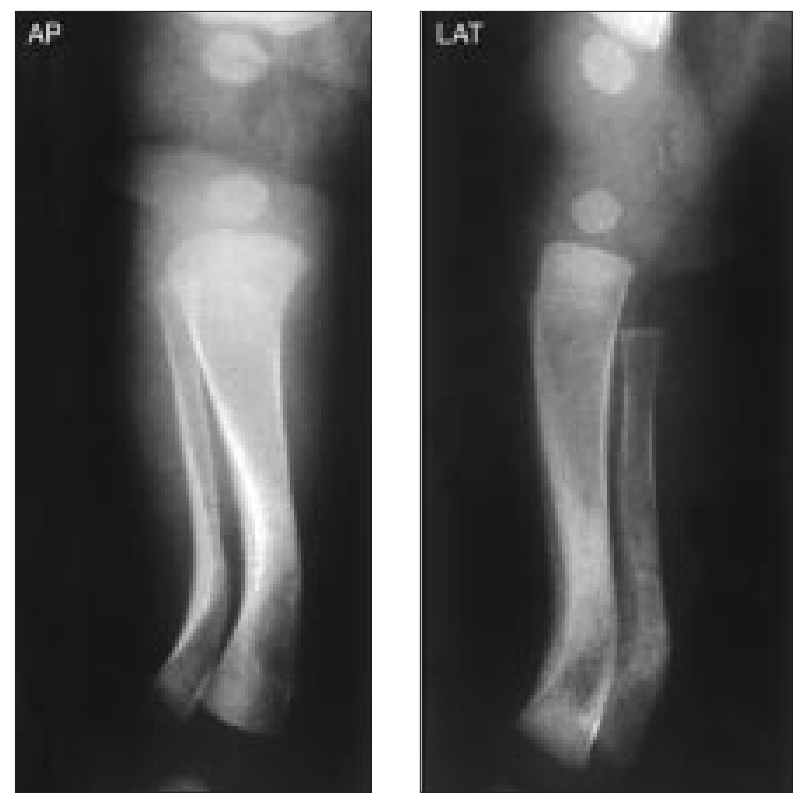

Figura 2. Radiografia anteroposterior y lateral de pierna izquierda a los 2 meses. Angulación posteromedial de tibia y peroné con esclerosis a nivel del ápex de la misma. Endomedular conservada.

\section{Correspondencia: Dr. J.L. Beguiristáin Gúrpide.}

Clínica Universitaria de Navarra. Pamplona.

Avda. Pío XII, s/n. 31008 Pamplona. España.

Correo electrónico: jbeguirist@unav.es, egarciab@unav.es

Recibido en abril de 2002.

Aceptado para su publicación en septiembre de 2002. 


\section{DEFORMIDADES ANGULARES CONGÉNITAS DE LA PIERNA/INCURVACIÓN CONGÉNITA DE TIBIA}

Las deformidades angulares congénitas de la pierna pueden ser de dos tipos:

1. Con el vértice de la angulación anterior y habitualmente externo.

2. Con el vértice de la angulación posterior y medial o interno.

Las deformidades angulares posteriores, como la de nuestro caso, muy probablemente se deban a falta de desarrollo de la porción superior de la tibia y peroné desde el período embrionario. La pantorrilla de la pierna afectada se atrofia y surge un grado variable de debilidad del tríceps sural, pero sin deformidad del pie o del tobillo ${ }^{1}$

La anomalía afecta a un lado y la tibia y el peroné mostrarán un acortamiento en grado variable, el peroné un poco más que la tibia. Después del año de vida el médico puede precisar la diferencia de longitud en miembros inferiores ya que es ésta habitualmente la única secuela de esta alteración ${ }^{1}$.

Las angulaciones anteromediales son más problemáticas debido a su posible asociación con la seudoartrosis congénita del hueso y aunque su causa es desconoci-
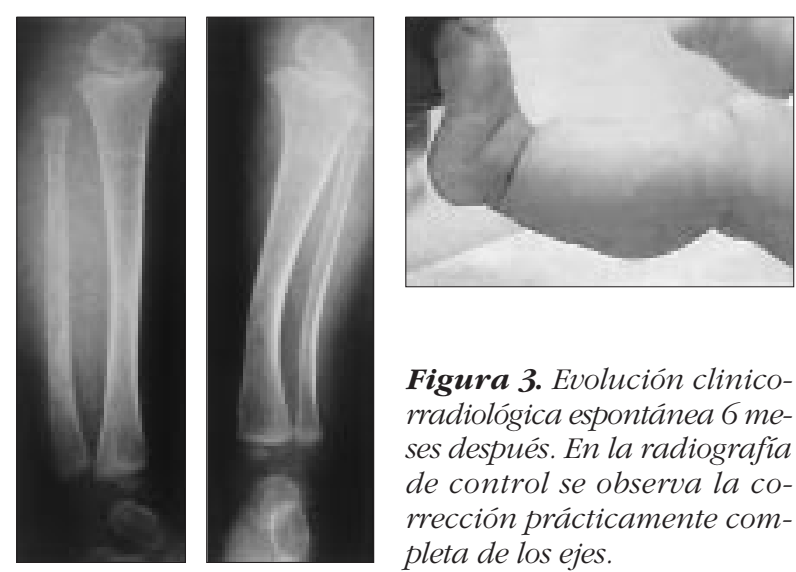

Figura 3. Evolución clinicorradiológica espontánea 6 meses después. En la radiografía de control se observa la corrección prácticamente completa de los ejes. da la asociación con la neurofibromatosis es muy alta (50-90\%) $)^{2}$. La relación precisa entre seudoartrosis y neurofibromatosis sigue siendo desconocida. Radiográficamente se observa la incurvación anterior con esclerosis en el vértice de la curva, estrechamiento del canal medular y alteraciones quísticas que indican fractura inminente. Una vez producida la fractura, los márgenes de los extremos óseos adyacentes se afilan más ${ }^{3}$. La resonancia magnética indica el tipo y la extensión de la enfermedad y está especialmente recomendada para valorar los cambios en periostio y partes blandas cercanas al foco de seudoartrosis ${ }^{4}$.

La edad del paciente, el patrón de anormalidades radiográficas (la presencia de quistes se asocian a mejor pronóstico) la dificultad para lograr la consolidación, y, si se obtiene, el acortamiento previsible del miembro y otras deformidades son factores que deben tenerse en cuenta al valorar el pronóstico y tratamiento ${ }^{1,2,3,5}$, quirúrgico antes del tercer año de edad5.

Por lo tanto, ante una deformidad angular de tibia, el pronóstico funcional va a venir determinado por el sentido de la angulación. Si fuera posteromedial la evolución habitual es la resolución espontánea. Se debe tranquilizar a los padres y sólo precisará seguimiento anual para detectar una posible dismetría (fig. 3).

\section{Bibliografía}

1. Tachdjian. Angulación posterointerna congénita de la tibia y el peroné. En: Tachdjian, editor. Pediatric Orthopedics, 2nd ed. Philadelphia: WB Saunders, 1990; p. 701-6.

2. Campbell. Deformidades angulares congénitas de la pierna. En: Campbell, editor. Cirugía Ortopédica, 9. ed. Terry Canale, 1998; p. $955-61$.

3. Resnick D. Otras anomalías y síndromes congénitos hereditarios. En: Resnick D, editor. Huesos y articulaciones en imagen, 2nd ed. Philadelphia: WB Saunders, 2001; p. 1185-6.

4. Mahnken AH, Staatz G, Hermanns B, Gunther RW, Weber M Congenital pseudoartrosis of the tibia in pediatric patients: MR Imaging. AJR Am J Roentgenol 2001;177:1025-9.

5. European Paediatric Orthopedic Society. Treatment approaches for congenital pseudoarthrosis of the tibia: Results of the EPOS multicenter study. J Pediatr Orthop B 2000;9:75-89. 